\title{
DESIGN OF DECY-13 CYCLOTRON DAQ SYSTEM
}

\author{
Ika Priyanti ${ }^{1}$, Adi Abimanyu ${ }^{2}$, Muhtadan $^{3}$, Saminto $^{4}$
}

1) Sekolah Tinggi Teknologi Nuklir, Yogyakarta, Indonesia, priyantika.elin@gmail.com

2) Sekolah Tinggi Teknologi Nuklir, Yogyakarta, Indonesia, abimanyu.avr@gmail.com

3) Sekolah Tinggi Teknologi Nuklir, Yogyakarta, Indonesia, muhtadan@batan.go.id

4) Pusat Sains dan Teknologi Akselerator, Yogyakarta, Indonesia, saminto@batan.go.id

\begin{abstract}
PSTA BATAN (Center of Science and Accelerator Technology) has been developed the $13 \mathrm{MeV}$ cyclotron named DECY-13 for producing radioisotope. That cyclotron has five subsystems and hasn't established by communication standard protocol yet. In order to make cyclotron communicate effectively, this paper presented the design of data acquisition with OPC (OLE for Process Control) based standard protocol and it has established in DECY-13's Instrumentation and Control System by case study method. We used Modbus TCP/IP architecture to make all of HMI from five subsystems building communication with each other to Server Computer (OPC Server). OPC Server and OPC Client has configured by NI OPC Server and NI LabVIEW. Data acquisition has monitored by LabVIEW. Configuration of the system for $13 \mathrm{MeV}$ cyclotron and performance test result showed in RMSE value from Reflected Drive Amp Power is 13,94\%, Magnetic Field is 11,2 \% ; Forward Final Amp Power is 5,24 \% ; Forward Drive Amp Power is 1,98 \%; MPS current is 1,87\%; Beam Current and A2 Sensor are 1,85\%; B2 Sensor is 1,77\% ; Bias Current is $1,71 \%$. Based on monitoring and test result, the design of DAQ system has succeeded and established the communication from several different data types from subsystems with OPC protocol standards.
\end{abstract}

Keyword : Cyclotron DECY-13, DAQ, Instrumentation system , OPC

\section{OVERVIEW}

Center of Science and Accelerator Technology (PSTA-BATAN) have been developed cyclotron with $13 \mathrm{MeV}$ energy named DECY-13 (Development of Experimental Cyclotron in Yogyakarta-13 $\mathrm{MeV})$. DECY-13 has 5 subsystems which are: Magnet system, Radio Frequency (RF) system, Ion Source system, Cooling system, and Vakum system. Each subsystems have different data type and different local controller. The differences of driver from any hardware and software obtained set of problems in Instrumentation and Control System. So, standard communication protocol properly needed in order to make server computer received the different data type each subsystems in good performances.

OPC was the standard communication protocol have been decided in this case study. OPC offering a special interoperability concept and the ease to fixed data acquisition system in DECY-13. Data acquisition based on OPC in DECY-13's instrumentation and control system was design for : (1) Connecting the server computer and client computer until the data can be sent, displayed and monitored through server computer., (2) Proposing the standard communication protocol which can be easily develop and flexible implementation, also to (3) supporting SCADA control system development in DECY-13 in the future.

\section{Cyclotron}

Cyclotron is circular accelerator that characterized by magnetic field and accelerating rf frequency which are constant in time [1]. Cyclotron accelerates some charged particle such as proton or electron. Accelerated proton in electric field obtained larger energy when radius increased because of deflection from magnetic field. When proton's energy was accomplished, it will hit the target and produced ${ }^{18} \mathrm{~F}$ radioisotopes which have 110 minutes half-time. This radioisotopes are use to detect cancer cells in human body [2]. Generally, cyclotron's support systems are integrating each other. They are consist of : magnet system, cooling system, RF system, ion source system dan 
vacuum system. Every component from each systems are shown in Figure 1.

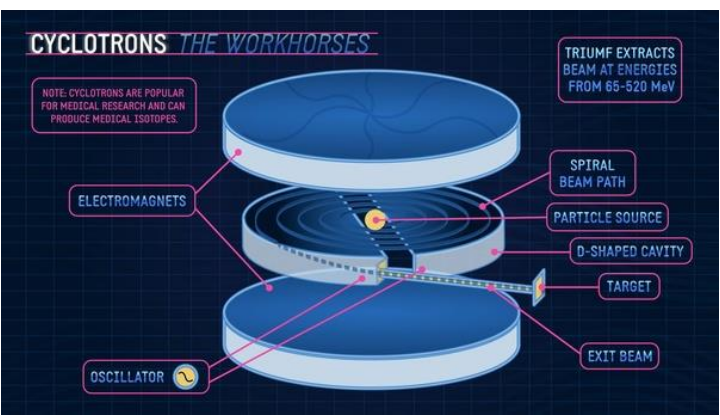

Figure 1. Cyclotron's support components[3].

Implementation of DECY-13's components are shown in Figure 2. The design was adapted from KIRAMS-13's Cyclotron (Korea) which are spesified by : PIG typed ion source with beam current production up to 100 $\mu \mathrm{A}$ in the center, magnetic field with $1,275 \mathrm{~T}$, maximum voltage of the dees are $40 \mathrm{kV}$ and $78 \mathrm{MHz}$ frequency, $13 \mathrm{MeV}$ proton energy, and proton beam current in the outer radius are kept at $50 \mu \mathrm{A}$ [1], [4].

(a)

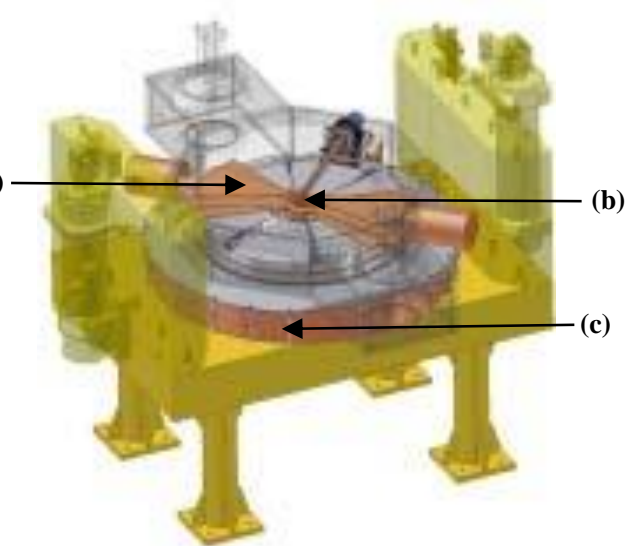

Figure 2. Overview of KIRAMS-13. (a) A couple of Dees, (b) A PIG type ion source, (c) Two magnetic poles. [4]

\section{OPC}

OPC (OLE for process control) is standard interface between numerous data sources, such as programmable logic controllers (PLCs), remote terminal units (RTUs), and sensors on a factory floor to HMI/SCADA applications, application tools, and databases. With OPC, deviceside server and application software can communicate without duplicating device driver development and providing support for hardware feature changes. The OPC
Foundation defines the standards that allow any client to access any OPCcompatible device[5].

\section{Data Acquisition}

Data acquisition is the process by which physical phenomena from the real world are transformed into electrical signals that are measured and converted into a digital format for processing, analysis, and storage by a computer. [7]

\section{Intrumentation and Control System}

The purpose of an instrumentation system used for making measurements is to give the user a numerical value corresponding to the variable being measured. A measurement system to have an input of the true value of the variable being measured and an output of the measured value of that variable [8].

\section{State Machine}

A state machine is a model of behavior composed of a finite number of states, transitions between those states, and actions. The State Machine approach in LabVIEW uses a Case structure inside a While loop to handle the different states in the program, and the transitions between them. The Shift Register is used to save data from and between the different states.

\section{Root Mean Square Error (RMSE)}

Root Mean Square Error (RMSE) is the standard deviation of the residuals (prediction errors). Residuals are a measure of how far from the regression line data points are; RMSE is a measure of how spread out these residuals are. In other words, it tells you how concentrated the data is around the line of best fit. Root mean square error is commonly used in climatology, forecasting, and regression analysis to verify experimental results. The RMSE formula is in Equation (1).

$$
R M S E=\sqrt{\sum_{I=1}^{N} \frac{\left(P_{i}-O_{i}\right)^{2}}{N}}
$$




\section{METHOD}

\section{Tools and Material}

This research were used five computers to represent five systems in DECY-13 and one server computer. Then, LabVIEW and NI OPC Server are the software tools. The material are got from the experiment logbook DECY-13.

\section{Design Process}

The system was designed with these following step :

1. Making list of the parameters and data type in every systems by did case study and observation.
2. Getting data, making a model by linier regression method and obtained the relation between the variables.

3. Creating the diagram block over systems which connected client computer (RTU) and server computer (MTU) by TCP/IP network. Diagram block is shown in Figure 3.

4. Creating algorithm of the programme, dataflow diagram, also configurating TCP/IP network. Programme algorithms are shown in Attachment I.

5. Configurating address list, modbus code function, tag address and data type every parameters. These configuration are shown in Table 1.

Table 1. Parameters in NI OPC Server Configuration

\begin{tabular}{|c|c|c|c|c|c|c|}
\hline SYSTEM & $\begin{array}{c}\text { START } \\
\text { ADD }\end{array}$ & ADDRESS & $\begin{array}{l}\text { DATA } \\
\text { TYPE }\end{array}$ & TAG ADDRESS & CODE & FUNCTION \\
\hline \multirow[t]{6}{*}{ COOLING } & 0 & $400001-2$ & Float & FLOW_DIFF PUMP1 & \multirow{6}{*}{$16(10 \mathrm{H})$} & \multirow{6}{*}{$\begin{array}{l}\text { Write Multiple } \\
\text { Register }\end{array}$} \\
\hline & & $400003-4$ & Float & FLOW_IS SYS & & \\
\hline & & 400005 & Word & FLOW_MAGNET COIL & & \\
\hline & & 400006 & Word & FLOW_RF SYS & & \\
\hline & & 400007 & Word & TEMP INPUT & & \\
\hline & & 400008 & Word & TEMP OUTPUT & & \\
\hline \multirow{14}{*}{$\begin{array}{c}\text { ION } \\
\text { SOURCE } \\
\end{array}$} & 9 & $400010-11$ & Float & BEAM CURRENT & \multirow{8}{*}{$16(10 \mathrm{H})$} & \multirow{8}{*}{$\begin{array}{l}\text { Write Multiple } \\
\text { Registers }\end{array}$} \\
\hline & & $400012-13$ & Float & BIAS CURRENT & & \\
\hline & & $400014-15$ & Float & VACUUM PRESSURE & & \\
\hline & & 400016-17 & Float & GAS FLOW & & \\
\hline & & 400018 & Word & BIAS VOLTAGE & & \\
\hline & & 400019 & Word & ISPS CURRENT & & \\
\hline & & 400020 & Word & ISPS VOLTAGE & & \\
\hline & & 400021 & Word & MPS CURRENT & & \\
\hline & 0 & 000001 & Boolean & ISPS READY & \multirow{6}{*}{$\begin{array}{c}15 \\
(0 \mathrm{FH})\end{array}$} & \multirow{6}{*}{$\begin{array}{l}\text { Write Multiple } \\
\text { Coils }\end{array}$} \\
\hline & & 000002 & Boolean & ISPS STATUS & & \\
\hline & & 000003 & Boolean & MAGNET PS & & \\
\hline & & 000004 & Boolean & HIGH VACUUM & & \\
\hline & & 000005 & Boolean & BIAS PS READY & & \\
\hline & & 000006 & Boolean & BIAS PS STATUS & & \\
\hline \multirow{10}{*}{ MAGNET } & 29 & 400030 & Word & CURRENT_PPM & \multirow{4}{*}{$16(10 \mathrm{H})$} & \multirow{4}{*}{$\begin{array}{c}\text { Write Multiple } \\
\text { Registers }\end{array}$} \\
\hline & & $400031-32$ & Float & CURRENT_A & & \\
\hline & & 400033-34 & Float & MF_T1 & & \\
\hline & & $400035-36$ & Float & MF_T2 & & \\
\hline & 7 & 000008 & Boolean & MAIN POWER & \multirow{6}{*}{$\begin{array}{c}15 \\
(0 \mathrm{FH})\end{array}$} & \multirow{6}{*}{$\begin{array}{l}\text { Write Multiple } \\
\text { Coils }\end{array}$} \\
\hline & & 000009 & Boolean & MPS NOT READY & & \\
\hline & & 000010 & Boolean & MAGNET OVERTEMP & & \\
\hline & & 000011 & Boolean & DC OVERLOAD & & \\
\hline & & 000012 & Boolean & DC OVERCURRENT & & \\
\hline & & 000013 & Boolean & OVER VOLTAGE & & \\
\hline \multirow[t]{17}{*}{ RF } & 39 & 400040 & Word & DDS_FW & \multirow{8}{*}{$16(10 \mathrm{H})$} & \multirow{8}{*}{$\begin{array}{c}\text { Write Multiple } \\
\text { Registers }\end{array}$} \\
\hline & & 400041 & Word & DDS_RE & & \\
\hline & & 400042 & Word & PA_FW & & \\
\hline & & 400043 & Word & PA_RE & & \\
\hline & & 400044 & Word & PF_FW & & \\
\hline & & 400045 & Word & PF_RE & & \\
\hline & & $400046-47$ & Float & RF_FREQ & & \\
\hline & & 400048 & Word & RF_VOLTAGE & & \\
\hline & 20 & 000021 & Boolean & DDS status & \multirow{3}{*}{$\begin{array}{c}15 \\
(0 \mathrm{FH})\end{array}$} & \multirow{3}{*}{$\begin{array}{l}\text { Write Multiple } \\
\text { Coils }\end{array}$} \\
\hline & & 000022 & Boolean & DA/PP status & & \\
\hline & & 000023 & Boolean & FA/PF Status & & \\
\hline & 50 & $400051-52$ & Float & SENSOR A2 & \multirow{2}{*}{$16(10 \mathrm{H})$} & \multirow{2}{*}{$\begin{array}{l}\text { Write Multiple } \\
\text { Registers }\end{array}$} \\
\hline & & 400053-54 & Float & SENSOR B2 & & \\
\hline & 15 & 000016 & Boolean & STATUS A2 & \multirow{4}{*}{$\begin{array}{c}15 \\
(0 \mathrm{FH})\end{array}$} & \multirow{4}{*}{$\begin{array}{l}\text { Write Multiple } \\
\text { Coils }\end{array}$} \\
\hline & & 000017 & Boolean & STATUS B2 & & \\
\hline & & 000018 & Boolean & STATUS RP & & \\
\hline & & 000019 & Boolean & STATUS DP & & \\
\hline
\end{tabular}




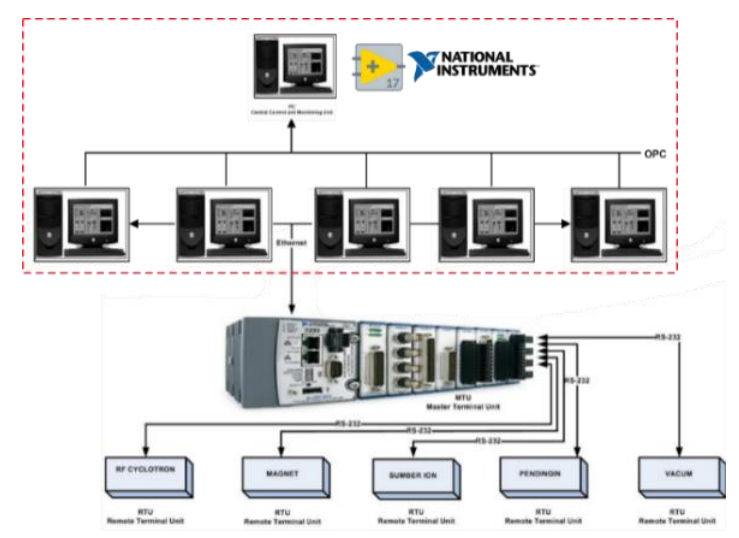

Figure 3. Diagram block of Data Acquisition System

\section{Implementation Process}

After designed process has been done, the next implementation systems are going to the following step :

1. Choosing the closest regression type with experiment data. The model are used to making a temporary data generator.

2. Writing the equation of the model to the LabVIEW programming by creating five "While Loop" for five systems.

3. Creating array data package and write them using Modbus library. "Write Multiple Register" mode for float and word data type,while "Write Multiple Coil" for boolean data type. Complete with configuration consisted with : starting address, data quantity, and data information. Starting address are listed in Table 1.

4. Sending that data package to OPC by monitoring it through OPC Quick Client by doing these step : Open NI OPC Server > Tools > Launch OPC Quick Client. Check the data in value column.

5. The next is creating HMI design in server computer and displaying all data indicator. Give the proper label to each indicator.HMI consist of 6 Tab pages, 1 is main page and the others are subsystem pages.

6. Making data binding between data package from NI OPC Server and LabVIEW HMI in server computer.

\section{Testing Process}

The purpose of testing process are to see the system performance. There are 2 kind of the test, quality communication test and error data test. The first one are going to the following step :

1. Opening the NI OPC Server to launch OPC Quick Client by click Tools> Launch OPC Quick Client.

2. Running the programme in client computer by Opening the VI LabVIEW in Project Cyclotron > Client Demo.VI

3. Checking the "quality" dan "value" di OPC Quick Client for each group tag. Starting from Cooling, Ion Source, Magnet, RF and Vacuum System.

4. Checking data that displayed in HMI server computer.

Then, error data test are done by the following step :

1. Exporting the data from HMI server computer table to Ms Excel by block all data tabel > right click > Export data to CSV/Excel.

2. Separating the data and counting the error by calculate the residual between the data that accepted to HMI server computer and the real data from experiment.

3. Counting the RMS Error value for each systems with formula that shown in Equation (1).

4. Displaying the RMSE data to table.

\section{RESULT}

This research has established through case study in order to implement the design of data acquisition system in DECY-13 based on OPC in PSTA-BATAN. Data source in the research came from experiment that have been done by researcher in Accelerator's Instrumentation and Control System Team. Then data have been analyzed by regression method and produce model. The model are use to make a data generator and send the data from client computer to server computer.

Model from data generator only use when this system did the simulation. But, after the system implemented into the real DECY-13, data flow came from the sensor like data acquisition as normally.

Interpolation result has been simulated by LabVIEW HMI. Then, data were sent to NI OPC Server and monitored by user through HMI LabVIEW in Server Computer. Result of the HMI are shown in Figure 4. 


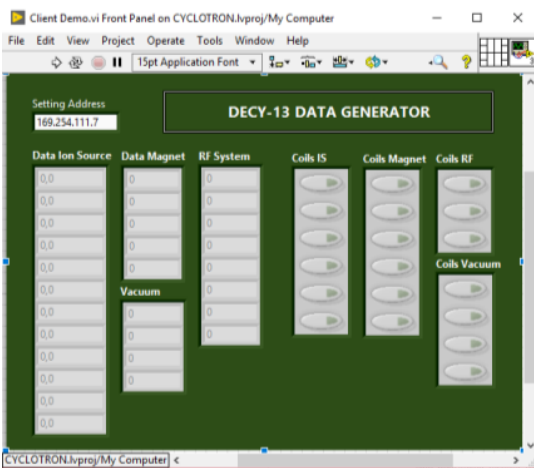

Figure 4. HMI Generator Data

These HMI represented five systems which using Modbus code function with command "Write multiple register" and "Write multiple coils". Write multiple register are using to produce array data package. Then data are wrote from starting address with data quantity information.

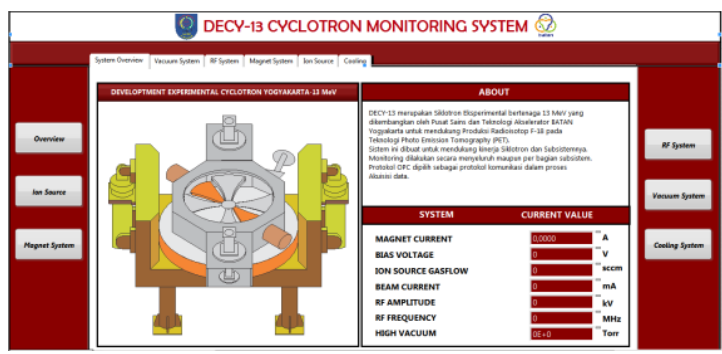

Figure 5. HMI Data Acquisition System: Cyclotron Overview page DECY-13 CYCLOTRON MONITORING SYSTEM Q

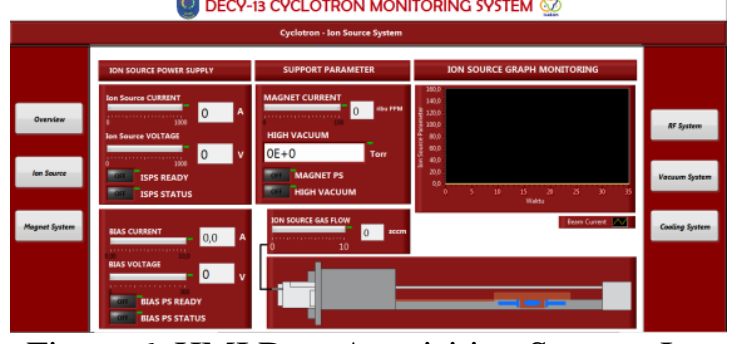

Figure 6. HMI Data Acquisition System: Ion Source System page

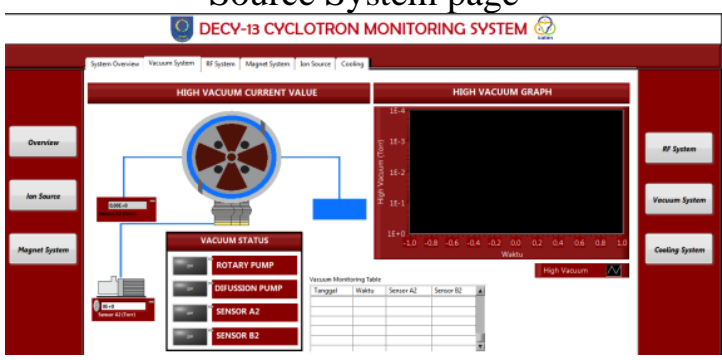

Figure 7. HMI Data Acquisition System: Vacuum Systems page

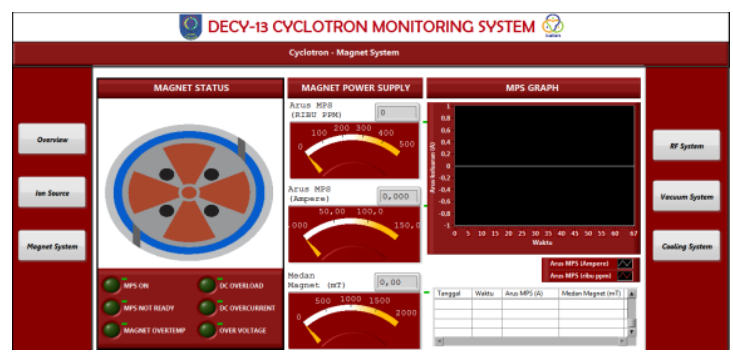

Figure 8. HMI Data Acquisition System: Magnet System Page

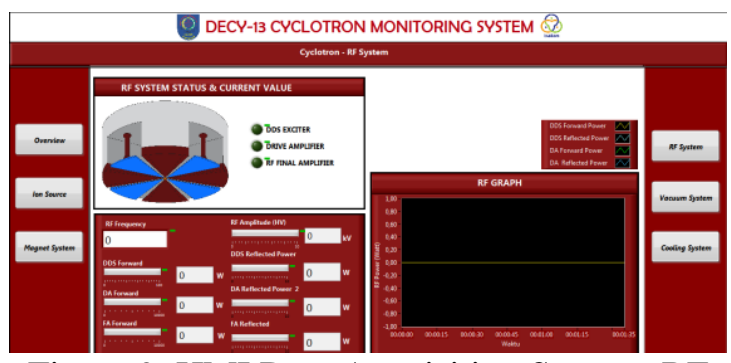

Figure 9. HMI Data Acquisition System: RF System page

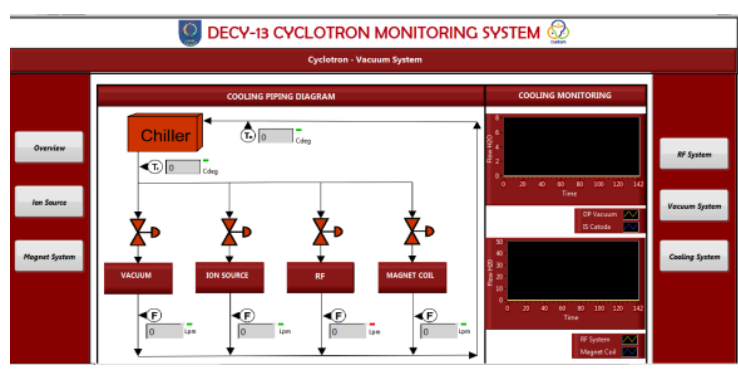

Figure 10. HMI Data Acquisition System: Cooling System page

\section{Testing Process}

From all displayed data, residual between them should be measured to see the error. Error data then processed by RMS Error method to test the system. RMSE test result are shown in Table 2.

Table 2. RMSE Test Result in Four Systems

\begin{tabular}{|c|c|c|}
\hline Subsystems & Parameter & RMSE (\%) \\
\hline $\begin{array}{c}\text { Magnet } \\
\text { System }\end{array}$ & MPS current (A) & 1,87 \\
\hline $\begin{array}{c}\text { Ion Source } \\
\text { System }\end{array}$ & Beagnetic field (mT) & 11,2 \\
\hline & $\begin{array}{c}\text { Bias Current (mA) } \\
\text { Forward Drive Amp } \\
\text { Power (Watt) }\end{array}$ & 1,71 \\
\hline \multirow{2}{*}{ Rystem } & $\begin{array}{c}\text { Reflected Drive Amp } \\
\text { Power (Watt) }\end{array}$ & 1,98 \\
\hline $\begin{array}{c}\text { Forward Final Amp } \\
\text { Power (Watt) }\end{array}$ & 13,94 \\
\hline $\begin{array}{c}\text { Vacuum } \\
\text { System }\end{array}$ & A2 Sensor (Torr) & 1,85 \\
\hline & B2 Sensor (Torr) & 1,77 \\
\hline
\end{tabular}


Table 2 showed RMSE value from 4 systems. The more RMSE value increased, the less accuracy system obtained and vice versa. The biggest RMSE value came from Reflected Drive Amplifier in RF System about 13,94 \%. This value actually is relatively error because of data weren't real-time mode. Although of data generator were delivered that error value, it won't influence the system when implemented into the cylotron system.

\section{CONCLUSION}

This paper introduces the OPC design for the data acquisition system of the DECY-13 cyclotron. It can simulate processes with welldesigned HMI. Data acquisition system based on OPC have been established in DECY-13's Instrumentation and Control system by case study and simulation. The implemented design kept data exchange between client computer and server computer.

RMSE value from Reflected Drive Amp Power 13,94 \%, Magnetic Field is 11,2 $\%$; Forward Final Amp Power is 5,24 \% ; Forward Drive Amp Power is 1,98 \% ; MPS current is $1,87 \%$; Beam Current and A2 Sensor are $1,85 \%$; B2 Sensor is $1,77 \%$; Bias Current is $1,71 \%$.

\section{REFERENCES}

1. Silakhudin, "PERSIAPAN DAN PROSEDUR PRE-COMMISSIONING SIKLOTRON DECY-13,” 2016. [Daring]. Tersedia pada: http://digilib.batan.go.id/eprosiding/File $\% 20$ Prosiding/Iptek $\% 20 \mathrm{~N}$ uklir/PPI_PSTA_2016/Data/24.\%20PPI \%20(151-157)\%20Silakhuddin.pdf.

[Diakses: 29-Jan-2018].

2. F. S. Permana, "HUMAN MACHINE INTERFACE BERBASIS LABVIEW UNTUK OPERASI SISTEM VAKUM SIKLOTRON PROTON DECY-13 MEV," Prosiding Pertemuan dan Presentasi Ilmiah - Penelitian Dasar Ilmu Pengetahuan dan Teknologi Nuklir 2016, 2016.

3. K. Mehra, "What Is The Principle of A Cyclotron? - Quora." [Daring]. Tersedia pada: https://www.quora.com/What-is- the-principle-of-a-cyclotron. [Diakses: 22-Jul-2018].

4. J. S. Chai, "DEVELOPMENT OF MEDICAL CYCLOTRON IN KIRAMS," Cyclotron Application Laboratory.

5. H.-P. Halvorsen, "OPC and RealTime Systems in LabVIEW." University College of Southeast Norway, 2016.

6. A. E. Putra, "Tutorial OPC (Bagian-3): Yayasan dan Spesifikasi OPC | DSP \& Embedded Electronics," 2009. .

7. J. Park dan S. Mackay, Practical Data Acquisition for Instrumentation and Control Systems. Burlington: Elsevier, 2003.

8. W. Bolton, Instrumentation and control systems, Repr. Amsterdam: Elsevier/Newnes, 2006. 